\title{
POLÍTICA SOCIAL E CAPITAL SOCIAL NO BRASIL DURANTE O GOVERNO LULA: UMA RELAÇÃO CONTRADITÓRIA ENTRE OS SETORES POPULARES
}

João Ignacio Pires Lucas

\begin{abstract}
Resumo
O objetivo deste trabalho é verificar o impacto dos Centros de Referência em Assistência Social - CRAS - na indução de capital social na população. Nesse sentido, foi realizado um survey com usuários do CRAS na cidade de Caxias do Sul no ano de 2009. A hipótese central deste trabalho é que os usuários não desenvolveram um comportamento político mais ativo, seja participando nos fóruns da própria política de assistência, seja participando de organizações políticas tradicionais, como partidos políticos e sindicatos. A pesquisa constatou que os usuários estão satisfeitos com os CRAS e com a política social, mas ainda não estão mobilizados e organizados politicamente.
\end{abstract}

Palavras-chave: Política Social; Capital Social; Participação Política; Democracia; Cultura Política.

\begin{abstract}
The aim of this study is to assess the impact of the Reference Center of Social Assistance - CRAS - in the induction of social capital in the population. Accordingly, a survey was conducted with users of CRAS in Caxias do Sul, 2009. The central hypothesis of this study is that users did not develop a more active political behavior by participating in the forums to the policy of assistance, either by participating in traditional political organizations like political parties and trade unions. The survey found that users are satisfied with the CRAS and social policy, but are not yet mobilized and organized politically.
\end{abstract}

Keywords: Social Policy; Social Capital; Political Participation; Democracy; Political Culture.

\section{Introdução}

O objetivo deste trabalho é analisar a relação entre a implementação do Sistema Único de Assistência Social (SUAS) ${ }^{1}$, particularmente no que

1 O SUAS foi instituído a partir de 2004 junto à Política Nacional de Assistência Social - PNAS
(MINISTÉRIO, 2004) e regulamentado com a aprovação da Norma Operacional Básica do Sistema
Único de Assistência Social (MINISTÉRIO, 2005). Importa ressaltar que o SUAS ainda não tem lei
específica, mas tramita na Câmara Federal um projeto de lei, PL $3077 / 2008$ (BRASIL, 2008) cuja
explicação da ementa está assim apresentada: "Estabelece objetivos para o Sistema Único de
Assistência Social (SUAS) e sua composição descentralizada e participativa, integrada pelos três
entes federativos; reduz para 65 (sessenta e cinco) anos a idade mínima para o idoso receber o 
concerne à organização e gestão dos Centros de Referência em Assistência Social (CRAS) e o nível de mobilização e participação política dos usuários, tendo em vista uma das diretrizes desta política pública: "participação da população, por meio de organizações representativas, na formulação das políticas e no controle das ações em todos os níveis" (BRASIL, 1993, art. 50, inciso II). Como a política pública de assistência social não apenas reconhece, mas quer, de certa forma, contribuir com a formação de um usuário autônomo e participativo, especialmente em relação à participação nas decisões sobre a condução da política social, esse texto busca verificar o padrão de organização dessa população.

Os dados apresentados foram obtidos através de uma pesquisa efetuada na cidade de Caxias do Sul ${ }^{2}$, Rio Grande do Sul, com o objetivo de identificar se houve e há algum peso nessa organização e participação por conta da ação do Estado, especialmente por intermédio da implementação da política nacional de assistência social básica referenciada nos Centros de Referência em Assistência Social - CRAS.

Conforme o disposto nas várias normativas definidoras da política pública de assistência social ${ }^{3}$, o SUAS é um sistema público que organiza, de forma descentralizada, os serviços socioassistenciais no Brasil em dois tipos de proteção social: "a proteção social de Assistência Social é hierarquizada em básica e especial ${ }^{4}$ e, ainda, tem níveis de complexidade do processo de

benefício de prestação continuada; define a proteção social básica e especial; cria o CRAS e CREAS" (p. 3).

2 A pesquisa em questão intitulada Avaliação dos Centros de Referência em Assistência Social CRAS - no município de Caxias do Sul, RS, foi desenvolvida na Universidade de Caxias do Sul, sob a coordenação da Profa. Mara de Oliveira. Essa pesquisa contou com os apoios da Fundação de Assistência Social - FAS -, da Prefeitura de Caxias do Sul e do CNPq.

3 Entre as várias normativas, leis; decretos, orientações, resoluções do Conselho Nacional de Assistência Social - CNAS, portarias do Ministério do Desenvolvimento e Combate a Fome (MDS) - salientam-se: Lei Orgânica de Seguridade Social - LOSS (1991); Lei Orgânica de Assistência Social - LOAS (1993); Política Nacional de Assistência Social - PNAS (2004); Programa de Atenção Integral as Famílias - PAIF: instruções para celebração de convênios (2004); Lei n. 10.836 (2004) Cria o Programa Bolsa Família e dá outras providências; Decreto n. 5.209 (2004) Regulamenta a Lei 10.836/2004 que cria o Programa Bolsa Família; Norma Operacional Básica NOB-SUAS (MINISTÉRIO, 2005); Norma Operacional Básica Recursos Humanos - NOB-RH (2006); Orientações Técnicas: Centro de Referência de Assistência Social - CRAS (2009); Tipificação Nacional de Serviços Socioassistenciais (2009).

4 Os serviços, programas e projetos de proteção social básica "tem como objetivos prevenir situações de risco por meio do desenvolvimento de potencialidades e aquisições, e o fortalecimento de vínculos familiares e comunitários. Destina-se à população que vive em situação de vulnerabilidade social decorrente da pobreza, privação (ausência de renda, precário ou nulo acesso aos serviços públicos, dentre outros) e, ou, fragilização de vínculos afetivos relacionais e de pertencimento social (discriminações etárias, étnicas, de gênero ou por deficiências, dentre outras). [...] A proteção social especial é a modalidade de atendimento assistencial destinada a famílias e indivíduos que se encontram em situação de risco pessoal e social, por ocorrência de abandono, maus tratos físicos e, ou, psíquicos, abuso sexual, uso de substâncias psicoativas, cumprimento de medidas sócio-educativas, situação de rua, situação de trabalho infantil, entre outras. São serviços que requerem acompanhamento individual e maior flexibilidade nas soluções protetivas. Da mesma forma, comportam encaminhamentos 
proteção, por decorrência do impacto desses riscos no indivíduo e em sua família" (MINISTÉRIO, 2005, p. 34). No caso da pesquisa ora apresentada, o foco da análise vincula-se aos serviços, programas, projetos e benefícios da proteção social básica.

Nesse sentido, esse trabalho procura articular uma análise estrutural e cultural ao mesmo tempo, na medida em que busca verificar o nível de organização e participação dos usuários a partir da investigação de fundamentos políticos e culturais motivadores do chamado capital social (que pode ser representado como o resultado positivo de tais motivações culturais, morais, políticas e ideológicas), ao lado do contexto da formação históricosocial em questão a partir do delineamento da atual fase do Estado brasileiro, dentro do contexto regional e global do sistema capitalista. Por isso, a parte estrutural além de impor um padrão constante de cultura política subalterna (OLIVEIRA, 2003) para os setores populares, também representa impactos conjunturais nas tradições associativas e políticas desses atores sociais, ainda que a base da cultura política brasileira tenha pesados condicionantes patrimonialistas e autoritários, patrocinadores de padrões de apatia política, por um lado, e de pouco associativismo político, por outro (SORJ e MARTUCCELLI, 2008).

Os estudos de Putnam (1996 e 2004), que são uma das principais referências na área e que geraram vários adeptos e seguidores, partem da cultura política cívica participativa como elemento chave para a construção e consolidação do capital social, uma espécie de musculatura robusta da sociedade civil em contraposição ao Estado. Porém, outros autores como Woolcock (1998), atribuem um peso para o próprio Estado na indução de capital social, especialmente nas circunstâncias em que não existe tal tradição na cultura política. Esse trabalho, portanto, segue a segunda orientação, procura verificar o peso do Estado na construção de uma cultura participativa.

Para o caso do Brasil, já foi bastante enfatizada a centralidade do Estado brasileiro no desenvolvimento humano e social, tanto no que concerne à efetivação de direitos sociais para uma população com altos índices de pobreza e marginalidade (SORJ e MARTUCCELLI, 2008), seja para o próprio desenvolvimento do capitalismo dependente, pois constituiu uma das bases do tripé do modelo de desenvolvimento nacional (junto com as empresas internacionais e o capital nacional). E do ponto de vista da cultura política, não foram poucas as vezes em que os cientistas sociais apontaram as fragilidades na implementação do Estado-Providência no Brasil, mesmo que depois da Segunda Grande Guerra Mundial esse fosse o padrão de Estado para o mundo ocidental. Porém, a tradição patrimonialista foi mais forte do que os impulsos modernizantes, a ponto de que a tradição cultural do favor tenha permanecido com relativa força na criação de um aparato jurídico e

monitorados, apoios e processos que assegurem qualidade na atenção protetiva e efetividade na reinserção almejada" (MINISTÉRIO, 2004, p. 19-32).

REVISTA DEBATES, Porto Alegre, v.5, n.1, p. 47-65, jan.-jun. 2011. 
político para os direitos e para as políticas sociais na segunda metade do século XX (MUNIZ, 2005).

Porém, ainda o Estado tem um papel a cumprir, mesmo para o incremento da sociedade civil, especialmente quanto a sua capacidade de participar nas principais decisões políticas, bem como na fiscalização dos atos do poder público. Nesse sentido, autores têm destacado o papel do Estado no desenvolvimento de práticas que redundem em capital social (WOOLCOCK, 1998), particularmente em contextos sociais e culturais como o brasileiro em que não há uma forte tradição de organização e participação da sociedade civil. Nesse sentido, verificar o nível de capital social no âmbito dos usuários das políticas sociais no Brasil deve servir para que algumas dessas discussões sejam tratadas de maneira empírica.

Segundo as projeções populacionais presentes na própria elaboração da PNAS (MINISTÉRIO, 2004), a população brasileira alvo das políticas sociais beira em torno dos 50 milhões, tendo como parâmetro as pessoas pertencentes às famílias consideradas num patamar mensal de renda abaixo da linha da pobreza (famílias com menos de $1 / 2$ salário mínimo mês). Se forem tratados os considerados em nível de indigência (famílias com menos de $1 / 4$ de salário mínimo mês), a população gira em torno dos 26 milhões. É importante destacarmos também que a população alvo dos programas de assistência social no Brasil é composta por pessoas desempregadas, idosas, crianças e jovens em situação de risco, isto é, uma população com vulnerabilidades sociais, culturais e econômicas, que demandam ações no âmbito da educação, tratamento psicológico, renda e emprego etc. Tal população, segundo o levantamento presente na própria PNAS (MINISTÉRIO, 2004), está dividida entre as grandes e pequenas cidades, sendo que nas grandes costuma morar nos bairros da periferia, demandando, dentre outras situações, auxílio no próprio transporte e deslocamento dentro da cidade.

Esse contexto social não pode passar despercebido nem das discussões sobre a consolidação da democracia no Brasil, especialmente de versões mais participativas, nem das discussões sobre as transformações globais ligadas aos valores materialistas. Nesse sentido, há uma aproximação de pressupostos entre os teóricos que têm discutido a evolução do desenvolvimento humano, que acaba impactando nos valores em nível da cultura política (INGLEHART e WELZEL, 2009), por um lado, com os autores que têm procurado avaliar o grau de organização e participação da sociedade civil, que possa redundar em capital social, de outro lado (BAQUERO e PRÁ, 2007). Porém, um país como o Brasil, que ainda possui uma grande parcela da população numa faixa que pode ser caracterizada como de vulnerabilidade e risco, tal articulação e debates não podem marginalizar os efeitos políticos ligados ao contexto social da pobreza.

A PNAS aprovada em 2004, no primeiro mandato do Governo Lula, representa uma evolução recente dessa política pública, bem como dos direitos sociais no Brasil, pois desde 1988 com a Constituição Federal, passando em 1993 pela aprovação da Lei Orgânica da Assistência Social - 
LOAS - esse país tem conseguido afirmar e programar ações de combate às vulnerabilidades sociais como a fome e o desemprego. Em 2004 também é o marco da aprovação do Sistema Único da Assistência Social - SUAS - que nos moldes do SUS - Sistema Único da Saúde - representa mais um passo na implementação de uma política pública descentralizada e com forte apelo à participação popular.

Nesse sentido, este trabalho procura avaliar os efeitos políticos presentes na interação entre a política social pública, voltada para a população mais carente, e a participação política da mesma na própria evolução da política.

Para tanto, o trabalho está dividido em três partes: na primeira, há uma discussão da política social no Brasil a partir de 2004, seus princípios, diretrizes e programas, destacando-se que a própria política social está baseada no princípio de que por mais vulnerável socialmente que seja o usuário, ele deve transforma-se num cidadão autônomo e participativo, o que também destaca a necessária articulação da política pública com a sociedade civil organizada. Na segunda parte, há um balanço sobre a literatura e estudos sobre o capital social em nível dos setores populares nas últimas décadas no Brasil, especialmente em relação à organização e participação política voltada para as políticas sociais, tanto no sentido da movimentação social reivindicativa, quanto na participação social crítica da política pública. $\mathrm{Na}$ terceira parte, são discutidos os resultados de uma pesquisa de opinião realizada em 2009, na cidade de Caxias do Sul/RS, com 638 usuários das políticas de assistência social.

A hipótese central do trabalho foca na contradição da política social no sentido de que ela ainda não conseguiu efetivar um cidadão autônomo e participativo, bem como a própria sociedade civil organizada dos setores populares não tem organização e participação suficiente para impor ações mais concretas tanto na elaboração das políticas sociais no Brasil, quanto na avaliação da efetivação de seus princípios (autonomia e gestão participativa).

Como resultado, especialmente a partir dos dados da pesquisa, constata-se que, pelo lado da sociedade civil em questão, a organização social dos setores populares tem fraca participação política geral, e especialmente nos órgãos políticos tradicionais (partidos, sindicatos, ONGs, associações de moradores), o que dificulta a consolidação de uma cultura política mais participativa e uma efetiva interação na elaboração e avaliação da política, e pelo lado da implementação da política social, não existe a efetivação dos princípios indutores da cidadania participativa.

\section{A política social no Brasil do governo Lula}

A política social no Governo Lula (2003-2010) tem alguns marcos que sinalizam os seus caminhos. Em 2004 é discutida e aprovada pelo Conselho Nacional de Assistência Social a nova Política Nacional de Assistência Social, como resultado das discussões da IV Conferência Nacional de Assistência 
Social de 2003. Dos principais símbolos alguns já vinham desde $1988 \mathrm{com}$ a Constituição Federal, e 1993 com a LOAS - Lei Orgânica da Assistência Social -, do Governo Itamar Franco, como no caso dos princípios da autonomia do cidadão e da universalidade do atendimento (num sistema não necessariamente contributivo), além das diretrizes de gestão baseadas na descentralização e controle social. Mas, o principal incremento foi a criação do Sistema Único de Assistência Social - SUAS - para coordenar todas as ações, nos moldes do SUS - Sistema Único de Saúde.

Nesse sentido, centrava-se na luta para a conquista de um cidadão autônomo (além do seu atendimento material), junto com a diretriz da descentralização que buscava integrar cada vez mais os entes federativos (Estados e Municípios) na gestão das políticas sociais, bem como o controle social pelo estímulo à ampla participação, seja da sociedade civil organizada, seja do próprio cidadão e dos usuários do sistema. Porém, tudo isso não foi tão marcante quanto o objetivo de superar o padrão histórico dos direitos e políticas sociais vistos como a (e dentro da) tradicional cultura do favor. A priorização da rede de assistência social básica e da família nos programas sociais que pudessem superar o mero repasse de bens materiais, como cestas básicas, bolsa família, passagem de ônibus etc., esteve ligado a esses objetivos. A proposta seria de viabilizarem-se programas baseados no fortalecimento da família e na capacitação profissional e política, bem como da capacitação para a participação nos fóruns de discussão do seu próprio atendimento (usuário), além da participação na elaboração da política social e nas mais diferentes atividades da vida em sociedade (MINISTÉRIO, 2004).

Antes de voltarmos à discussão da PNAS, a política social no Governo Lula não pode ser avaliada sem a devida contextualização das variáveis globais e locais no que concerne tanto aos recursos necessários para a implementação dos programas pretendidos, quanto em relação aos aspectos políticos e ideológicos. Na Europa, por exemplo, a construção do EstadoProvidência ao longo do século XX esteve ligada a uma fase do capitalismo (SANTOS, 2002), do chamado capitalismo organizado, que, dentre outras questões, representou uma fase especial da articulação entre os setores sociais e políticos que falavam em nome do capital e do trabalho (como os sindicatos). Porém, a relação de dependência existente dos países periféricos com esses países europeus também contribuiu para que existisse uma grande acumulação de recursos que foram repassados aos trabalhadores e demais detentores dos direitos sociais (MARINI, 2000). Isso não existiu nem para Lula no Brasil, nem para os seus colegas da América Latina como Venezuela, Equador, Argentina, Uruguai. O Brasil e a América Latina não gozam de uma mesma condição para a implementação no início do século XXI daquela que aconteceu na Europa depois da Segunda Grande Guerra. Isso de um lado.

De outro lado, já faz mais de uma década que o crescimento da China, e de outros países da Ásia - à exceção do Japão -, ao lado da estagnação dos chamados países de primeiro mundo, como os Estados Unidos e os países da Europa Ocidental (Inglaterra, França, Alemanha, Itália, Espanha, etc.), vêm 
colocando novas demandas para a construção dos direitos sociais e das políticas públicas sociais nos países em desenvolvimento como o Brasil e demais países da América Latina. Autores como Amin (2006), Santos (2004), Arrighi (2008), dentre outros, têm destacado que na nova fase da divisão internacional do trabalho do sistema capitalista global, os países da Ásia, especialmente a China e Índia, estão recebendo investimentos pesados em infraestrutura e desenvolvimento econômico moderno, ou seja, de acordo com os padrões do século XX (industrialização e urbanização), enquanto que países como os da América Latina têm ficado com as sobras e pequenos investimentos. Como principal desdobramento, quase todo o processo de desenvolvimento desses países depende da poupança interna muitas vezes conquistada a partir da exploração de recursos naturais como o petróleo, gás etc. Nesse sentido, como não há grandes somas de recursos disponíveis para o desenvolvimento dos países latino americanos, e como as suas economias são frágeis no sentido da acumulação de capital que possa suportar tais investimentos, cabe quase que exclusivamente ao poder público tentar inverter recursos acumulados na venda de bens naturais em políticas públicas sociais de inclusão. Isso faz com que o processo social e econômico seja limitado em termos dos recursos disponíveis.

Hobsbawm (1992) comentou que, de certa forma, a URSS salvou o capitalismo com a sua vitória sobre a Alemanha nazista na Segunda Grande Guerra Mundial, mas também com a sua versão stalinista do socialismo. No momento atual, da mesma maneira, a China socialista também não deixa de ser um suporte fundamental para a expansão do capitalismo mesmo com toda a estagnação presente nas economias mais desenvolvidas. Se no século XXI há toda uma discussão sobre as tecnologias virtuais estarem transformando o trabalho manual em algo obsoleto (LIMA, 2008) e se as grandes empresas no ocidente estão já modificando as suas formas de gestão e organização do trabalho, é porque existe, de outro lado, a super exploração do trabalho na China e noutros países da Ásia, assim como já ocorreu com países da América Latina (Brasil, México, Argentina, Chile). E um dos desdobramentos disso dáse pelo lado cultural, pois a emergência de uma sociedade tanto da informação quanto do consumo não contribui para o incremento de participação social da população mundial, muito menos dos países periféricos rotulados de emergentes.

Se um país como o Brasil não é estratégico para o desenvolvimento do capitalismo agora na sua versão de economia mundial e de divisão do trabalho na globalização, a possibilidade de indução de capital social na sua população para além apenas do ganho material é um desafio enorme porque as próprias construções culturais e políticas estão em crise na modernidade (SENNETT, 2006 e 2009). Os partidos e demais instituições políticas que tanto serviam para a manutenção do poder como para a sua transformação estão em uma crise muito forte, especialmente no recrutamento de novas lideranças que tenham capacidade de mobilização da sociedade civil. A própria cultura 
individualista atua negativamente na perspectiva do indivíduo racional que busca vantagens individuais no cenário social atual (JAMESON, 1997 e 2005).

Além disso, a esfera política no Brasil está ainda muito marcada pelos argumentos neoliberais, que causaram tantos transtornos nas políticas públicas e na força do Estado em ser um indutor do desenvolvimento. $O$ momento é outro, e nele o papel do Estado não pode ser mais ou mesmo, ainda que no caso do Brasil a perspectiva política ligada às políticas sociais de inclusão sejam voltadas para não apenas a própria inclusão, mas o desenvolvimento de uma cidadania crítica, autônoma e participativa (MINISTÉRIO, 2004). Nos anos de 2003 a 2009, do Governo Lula, o Brasil conseguiu um crescimento econômico intermediário (entre a estagnação da Europa e EUA e super crescimento da China e Índia), bem como uma visível evolução na implementação dos direitos sociais e das políticas públicas no campo da inclusão social. Isso aconteceu depois de uma longa fase inicial desde 1930 de implementação da seguridade social tanto no Brasil quanto na América Latina (BOSCHETTI, 2009). Porém, ainda antes dos anos 2000, o neoliberalismo do final dos anos 80 e da década de 90 impôs certo revés nessa evolução (ROJAS COUTO, 2006). Só que a ideologia do favor, as relações política do Estado federativo, a atuação da burocracia e a fragilidade organizacional da população brasileira e a necessidade material são impedimentos que dificultam tal situação. E a sociedade civil é um dos pontos que pode reverter isso.

\section{Capital social no Brasil}

São muitos os desafios presentes no processo de construção de uma cultura política democrática e participativa no Brasil e na América Latina. No mínimo, vários estudos voltados aos aspectos culturais da tradição política brasileira têm apontado o peso da tradição autoritária e clientelista que acompanha o Brasil desde a sua invenção no século XVI, sem falarmos nas questões ligadas à pobreza e à marginalidade nos grandes centros urbanos e áreas rurais (SORJ e MARTUCCELLI, 2008). Também, se os problemas anteriores já não fossem suficientes, os movimentos sociais que furaram tais bloqueios e até conseguiram alguma mobilização social a partir da luta pelo fim da ditadura militar e pela emergência de novos atores no cenário político (ANDRADE, 2010), a partir da vitória de Lula nas eleições presidenciais de 2002, têm partes significativas (especialmente os movimentos sociais ligados ao Partido dos Trabalhadores - PT - e aos partidos socialistas como o Partido Socialista Brasileiro - PSB - e Partido Comunista do Brasil - PCdoB) dentro do Governo Federal ou em apoio aberto ao mesmo.

E como já foi comentado acima, o Estado brasileiro tem tido uma relação contraditória com a sociedade civil e os movimentos sociais. Ora ele é apoiador e incentivador da própria mobilização social, como na criação dos SUS e dos Conselhos Gestores das políticas públicas (educação, cultura, assistência social), ora ele coopta e tutela a sociedade civil (na relação com as 
entidades sindicais, com os partidos políticos). Nesse sentido, por mais que a sociedade civil brasileira tenha demonstrado uma relativa cultura participativa a partir da luta contra a ditadura, a partir dos anos 90 do século XX tal iniciativa foi sendo solapada. Dois motivos opostos foram importantes para isso: um deles foi a emergência do neoliberalismo, que colocou na defensiva muitos movimento sociais, além da própria afirmação da política de assistência social (ROJAS COUTO, 2006; PEREIRA, 2009; OLIVEIRA, 2009); mas um outro motivo posterior (já nos anos 2000) foi dado pelas vitórias eleitorais da esquerda em governos estaduais e federal.

Duas correntes teóricas convergem quanto aos resultados de suas pesquisas e análises. Pelo lado dos estudos da cultura política (com outras contribuições no campo do individualismo metodológico, institucionalismo, etc.), como os estudos de Moisés (1995), Baquero (1999), e tantos outros, até são verificados conexões entre aspectos da cultura política com certa organização política e determinados eventos de mobilização social, motivados por graus de confiança, mas que no geral, não servem como um padrão generalizado para o conjunto da sociedade civil.

No caso ainda dos setores populares, além da manutenção de graus de desconfiança e apatia política em relação ao padrão tradicional de instituições (partidos, sindicatos, congresso) e de comportamento político (manifestações de rua, greves, passeatas), há um contexto cultural e social no qual um determinado movimento social exerce um peso significativo, que é o caso da religiosidade, bem como certas igrejas (não mais apenas a católica, mas cada vez mais as evangélicas pentecostais) assumem um papel crucial como referência política e de agregadora de vínculos sociais (SORJ e MARTUCCELLI, 2008).

A síntese é de que os brasileiros até simpatizam difusamente com a democracia, mas nos atos específicos há uma defasagem de aceitação e apoio (BAQUERO, 1999; BAQUERO e PRÁ, 2007). Ou os brasileiros não confiam nas suas instituições, com baixos índices de confiança e interesse (MOISÉS, 1995; LUCAS, 2004).

Também do lado de outra tradição, há vários estudos tratando da subalternidade reforçada ainda que tenha havido toda uma construção da cidadania via o Estado democrático de Direito (ABREU, 2008). Isso fica mais visível no tratamento histórico da evolução dos direitos sociais e das políticas sociais voltadas geralmente para os de baixo. Essa situação já teve um padrão histórico de exclusão e da inclusão tutelada dos setores subalternos. Primeiro foi no âmbito do mundo trabalho urbano, com o populismo de muitas versões. Depois, com as políticas sociais foi sendo feito a ampliação para os marginalizados. Porém, ficaram segmentos ainda marginalizados. Outro aspecto foi a da cultura do favor. Mesmo que já existissem políticas, recursos e programa, a lógica de inclusão via o discurso, mas especialmente a prática dos profissionais diretamente envolvidos, assistentes sociais, funcionários públicos, foi sendo mantido um padrão que por mais que o Estado estivesse 
ligado a isso não produzia resultados para além de ganhos materiais da população. E a organização servia de recrutamento e cooptação.

\section{Os usuários dos programas de assistência social}

No ano de 2009 foi realizada uma pesquisa de opinião com 638 usuários dos programas de assistência social de Caxias do Sul, um município da serra gaúcha com mais de 400 mil habitantes. A base de dados que serviu para a seleção dos entrevistados foi a lista de usuários cadastrados nos CRAS - Centros de Referência em Assistência Social - de Caxias do Sul. Os usuários cadastrados são aqueles que, a despeito de terem muitas vezes procurado o CRAS para a simples obtenção de um vale transporte ou cesta básica, já foram incluídos em algum programa de atendimento sistemático, como, por exemplo, o PAIF - Programa de Atenção Integral à Família.

Os CRAS surgiram com a nova PNAS de 2004 para, preferencialmente, o atendimento sócio-familiar. Cada um deles deve atender um total de 1000 famílias nos seus mais diferentes programas, inclusive no PAIF. Os usuários são cadastrados a partir do momento em que eles frequentam, com certa assiduidade, esses centros, e dessas listas foi feito um sorteio aleatório para as entrevistas. Em geral, essa assiduidade é fruto de atendimento material (cestas básicas, bolsa família), que deve ser intermediado com outros programas que busquem a capacitação não só dos usuários de forma individual, mas das suas famílias. A assistência social básica difere de uma mais especializada que é atendida pelo CREAS - Centro de Referência Especializado em Assistência Social -, pois a básica ainda não representou o rompimento dos laços familiares (drogas, violência, separação). Seus usuários, da assistência básica, muitas vezes buscam o CRAS para receberem apenas um vale transporte ou cesta básica, depois nunca mais voltam.

O perfil social dos entrevistados revela as condições da população em situação de vulnerabilidade prevista na política de assistência social referenciada no CRAS. Do total de entrevistados, 93\% são mulheres, $76 \%$ ou são analfabetos ou têm apenas o ensino fundamental incompleto, $53 \%$ são pessoas que trabalham em suas próprias casas na categoria tradicional do lar e $54 \%$ têm até um salário mínimo como renda mensal familiar. É claro, os homens também são atendidos nos CRAS, mas esse resultado não deixa de sinalizar para o contexto sócio-familiar em que são realmente as mulheres que acabam não apenas procurando mais atendimento nas políticas de assistência, bem como são as mulheres, também, que participam mais dos programas oferecidos na política assistencial.

As tabelas elencadas abaixo, de 1 a 5, trazem informações acerca da participação política e social desses entrevistados, além das suas opiniões sobre vários aspectos da política social, desde o tipo de atendimento recebido, e percebido, até o grau de satisfação em relação a esses contatos diretos com a implementação da política social. Pelo tipo de contato que os usuários desenvolvem junto aos CRAS e a política de assistência social prevista na 
PNAS, a pesquisa foi direcionada diretamente para questionamentos que permitissem uma avaliação do atendimento recebido, o seu grau de satisfação, e de como o usuário em linhas gerais enquadra a política de assistência, na figura do próprio CRAS na dicotomia do direito ou do favor. É claro, tal questão, do direito e favor, mediada pelo tipo de procura que o usuário tem, e pelo tipo de entendimento que ele deposita no CRAS, além da articulação dessas noções com a sua visão de atendimento e relacionamento com os técnicos e profissionais dos centros.

Os dados estão divididos em três itens: (1) a participação política; (2) percepção sobre o atendimento e sua avaliação; (3) a política social como direito ou favor.

Sobre a participação política, as Tabelas 1 e 2 trazem informações sobre a participação política e social sistemática dos entrevistados e o tipo de movimento em que eles participam.

Tabela 1 - Usuários dos CRAS que participam nos movimentos sociais. Caxias do Sul, 2009.

\begin{tabular}{ccc}
\hline Participação & $\mathbf{f}$ & \% \\
\hline Não participa & 526 & 82 \\
Participa & 112 & 18 \\
\hline Total & 638 & 100
\end{tabular}

Fonte: Pesquisa Avaliação dos CRAS de Caxias do Sul, 2009.

Tabela 2 - Tipo de movimento social ou político que participa.

\begin{tabular}{cc}
\multicolumn{2}{c}{ Caxias do Sul, 2009. } \\
\hline Tipo de movimento & \% dos que participam \\
\hline Partido político & $3^{*}$ \\
Sindicato & 2 \\
Associação de Moradores & 26 \\
Clube de Mães & 11 \\
Pastorais & 63 \\
\hline Fonte: Pesquisa Avaliação dos CRAS de Caxias do Sul, 2009. \\
*Os entrevistados puderam responder mais de uma opção.
\end{tabular}

A pesquisa foi realizada no segundo semestre de 2009 e a grande maioria dos entrevistados já vinham tendo contato com os programas sociais desenvolvidos nos CRAS desde os anos de 2004 e 2005. Mesmo assim, a quantidade de usuários que milita nos movimentos sociais e políticos não é superior ao padrão da participação política brasileira e da própria cidade de Caxias do Sul. Ou seja, não se percebe um incremento de organização e participação entre os usuários diferente daquele já existente no padrão da população brasileira. 
Dos movimentos sociais e políticos que foram citados pelos entrevistados que participam, os mais lembrados foram os movimentos sociais que nem têm uma conotação diretamente política ou partidária. As pastorais, com $63 \%$, o movimento comunitário das associações de moradores, com $26 \%$ e os clubes de mães, com $11 \%$, não deixam de estar num mesmo enfoque de participação: ligado ao lugar de moradia, condição de gênero e religião. De certa maneira, esses dados corroboram as reflexões de Sorj e Martuccelli (2008), quando esses autores afirmam que os movimentos sociais ligados à religião e religiosidade estão entre os principais para os setores populares. Por outro lado, é de se esperar que certos movimentos políticos como o sindical não seja muito frequentado porque os entrevistados trabalhadores formais são minoria. Mas, o caso dos partidos políticos é realmente crítico, nem para aqueles setores que possuem fortes demandas sociais. Nem para esses segmentos os partidos políticos parecem representar uma opção concreta de solução dos seus problemas.

A pouca participação política dos entrevistados também é verificada nos próprios CRAS, pois apenas $9 \%$ dos usuários responderam afirmativamente quanto questionados se havia participado de alguma atividade nesses centros (atividades não diretamente ligadas aos seus atendimentos ${ }^{5}$ ). Na comunidade, seja nas Associações de Moradores - AMOB ou outras instituições - como as igrejas, clubes de mães -, também apenas $8 \%$ dos entrevistados afirmaram ter participado de alguma reunião ou atividade em que os CRAS ou a política social estivessem em discussão. E as poucas pessoas que participaram de alguma discussão na comunidade, foram na $A M O B$ do bairro.

De uma forma direta, então, não se percebe pelos dados da pesquisa que a participação social ou política dos entrevistados em movimentos e instituições tenha tido um acréscimo significativo. Os resultados confirmam um padrão de relativa apatia no que concerne à participação política, especialmente nos partidos políticos.

Os dados sobre os tipos de atendimento e sobre a demanda prioritária que os usuários têm, na nossa visão, mostram motivos para tal resultado.

Sobre as demandas e o atendimento, as próximas três tabelas, 3, 4 e 5 , informam sobre as respostas dos entrevistados sobre os seus atendimentos nos CRAS. As informações já mostram as respostas dos dois grupos de entrevistados, os que não participam e os que participam. Para os dois grupos, a maioria dos usuários respondeu que os técnicos não perguntaram sobre as propostas deles (para o atendimento), nem o que os entrevistados achavam das suas próprias situações (que estavam merecendo atendimento). Dos dois grupos, os usuários que disseram participar de movimentos sociais e políticos foram os que mais tiveram interação positiva com os técnicos (cerca de $35 \%$ respondem sim, que haviam sido perguntados).

\footnotetext{
5 Como na participação dos Conselhos Gestores, por exemplo, ou em alguma reunião para a definição da política social.
} 
Dois aspectos teóricos são importantes para essas questões. De um lado, o tal incentivo ao protagonismo social e político que pode ser motivado pela PNAS deveria começar, no mínimo, pelo próprio atendimento realizado dentro dos programas de assistência, justamente para quebrar-se com o padrão da tradição política e cultural que reforçava (e reforça) a cultura do favor, especialmente para as políticas e direitos dos setores populares. É claro, um dos principais elementos da política social é a questão material, no sentido de que a população vulnerável possa obter recursos materiais para a sua sobrevivência. Porém, como a nova política social os CRAS e os programas lá desenvolvidos pretendem-se indutores da cidadania ativa e autônoma, não se reproduzindo mais no momento da prática da política aquelas velhas formas tradicionais do favor. Por isso, mesmo que $1 / 3$ dos usuários militantes de movimentos sociais e políticos tenham respondido que haviam tido uma interação mais dialogada com os técnicos, os resultados gerais são inadequados do ponto de vista da indução à participação.

Tabela 3 - Participação e atendimento dos técnicos dos CRAS. Caxias do Sul, 2009.

\begin{tabular}{|c|c|c|c|}
\hline \multirow[t]{2}{*}{ Participa } & \multicolumn{2}{|c|}{$\begin{array}{c}\text { O técnico pergunta sobre } \\
\text { as propostas deles? }\end{array}$} & \multirow[t]{2}{*}{ Total } \\
\hline & Sim & Não & \\
\hline Não participa & $99 \quad(20 \%)$ & $416 \quad(80 \%)$ & $515 \quad(100 \%)$ \\
\hline Participa & $39(35 \%)$ & $72(65 \%)$ & $111(100 \%)$ \\
\hline
\end{tabular}

Fonte: Pesquisa Avaliação dos CRAS de Caxias do Sul, 2009.

Tabela 4 - Participação em movimentos e atendimento nos CRAS. Caxias do Sul, 2009.

\begin{tabular}{|c|c|c|c|}
\hline \multirow[t]{2}{*}{ Participa } & \multicolumn{2}{|c|}{$\begin{array}{c}\text { O técnico pergunta o que o sr. } \\
\text { acha da sua situação? }\end{array}$} & \multirow[t]{2}{*}{ Total } \\
\hline & Sim & Não & \\
\hline Não participa & $144 \quad(28 \%)$ & $371 \quad(72 \%)$ & $515 \quad(100 \%)$ \\
\hline Participa & $39(35 \%)$ & $72(65 \%)$ & $111(100 \%)$ \\
\hline
\end{tabular}

Fonte: Pesquisa Avaliação dos CRAS de Caxias do Sul, 2009.

De outro lado, essa ainda pouca interação não significou uma avaliação negativa do atendimento e do trabalho dos técnicos. Para esse tipo de resultado, as proporções mudam, a esmagadora maioria dos entrevistados estava satisfeita. Sendo que os militantes afirmaram estarem ainda mais satisfeitos que os não militantes (ver a Tabela 5). 
Tabela 5 - Participação e satisfação com o trabalho dos técnicos?

\begin{tabular}{|c|c|c|c|}
\hline Participação & Satisfação & $f$ & $\%$ \\
\hline \multirow{2}{*}{ Não participa } & Insatisfeito & 124 & 25 \\
\hline & Satisfeito & 394 & 75 \\
\hline \multirow{2}{*}{ Participa } & Insatisfeito & 16 & 15 \\
\hline & Satisfeito & 95 & 85 \\
\hline
\end{tabular}

Esses percentuais de satisfação também são dessa proporção em relação ao CRAS como um todo e em relação à política social de uma forma geral. Ou seja, podemos inferir que os usuários das políticas sociais, uma população marcada pela vulnerabilidade e riscos, estão satisfeitos com a atuação do Estado, particularmente àquele com a qual eles interagem diretamente (nos CRAS). Porém, de forma mais detalhada, tal satisfação, sobre os principais motivos, está ligada às questões materiais, isto é, ao atendimento às demandas concretas em termos de cestas básicas e outras formas de recursos.

Cerca de $62 \%$ dos entrevistados afirmaram procurar no CRAS apenas apoio material, ou, no mínimo, esse tipo de apoio era o mais importante. Nesse sentido, não é contraditório o resultado que aponta satisfação por parte dos usuários, eles até chegam a confiar nos programas sociais e técnicos ${ }^{6}$ uma regra positiva para o acúmulo de capital social -, porém, tal apoio e satisfação têm no elemento material o aspecto fundamental, o que acaba não produzindo efeitos positivos em termos da participação e organização política. Tal resultado verificado contribui com a noção de que para o efetivo incremento de participação é necessário mais do que a mera satisfação e o mero atendimento material.

Se a discussão migrar para o papel do Estado no processo de acumulação de capital social, pode-se constatar, também, que por mais que ele contribua com a parte das políticas sociais, atendendo às demandas materiais, ele não contribui integralmente se não praticar um tipo de implementação da política (atendimento) de forma democrática e cidadã.

Para a população vulnerável, o incremento do capital social que redunde em maior participação e organização política não pode depender apenas do atendimento material. Isso é muito importante para a inclusão social dos setores populares, mas não produz efeitos significativos do ponto de vista da política.

Numa outra perspectiva, a mera satisfação com 0 atendimento material e com a atuação dos representantes do Estado não produz efeitos de capital social que levem ao incremento da participação. Ou seja, dois dos elementos mais importantes da literatura sobre o capital social (a satisfação e o atendimento material) não produziram efeitos significativos no estudo em

\footnotetext{
${ }^{6}$ Isso também aferido pelas respostas qualitativas de aprovação dos CRAS e dos técnicos.
} 
questão. A hipótese para tal falta de efeito, na nossa visão, está ligada ao peso da cultura política do favor.

A cultura do favor ainda pesa significativamente para que apenas o atendimento material e a satisfação com a atuação do Estado possam redundar em capital social (e em organização e participação política). A Tabela 6 informa sobre a associação de duas variáveis (a dos usuários que buscaram apoio material - ou não - e uma que traduzia a questão da política social e do CRAS ser um direito ou um favor). Por mais que a associação das variáveis seja baixa ( $V$ de Cramer de 0,137 - com 0,01 de significância), pode-se perceber que os usuários que buscam basicamente apenas apoio material apontam o CRAS (a PNAS na prática) como favor, em maior proporção do que os usuários que buscam outros recursos nos CRAS (como cursos, atendimento psicológico etc.). De uma maneira geral, os entrevistados dividiram-se na questão do direito e do favor, e por mais que o resultado não tenha sido muito diferente entre os entrevistados que buscam o apoio material, a tendência é que a visão da política como sendo algo para além do mero apoio material parece indicar uma afirmação da cidadania ativa.

Tabela 6 - Busca de apoio material e cultura do favor. Caxias do Sul, 2009.

\begin{tabular}{c|ccc}
\hline \multirow{2}{*}{ Busca de apoio material } & \multicolumn{3}{|c}{ O trabalho do CRAS é um direito ou favor? } \\
\cline { 2 - 3 } & \multicolumn{2}{|c}{ Direito } & \multicolumn{1}{c}{ Favor } \\
\hline Não apoio material & 141 & $(59 \%)$ & $100(41 \%)$ \\
Apoio material & $176 \quad(44 \%)$ & $221 \quad(56 \%)$ \\
\hline
\end{tabular}

Fonte: Pesquisa Avaliação dos CRAS de Caxias do Sul, 2009.

A percepção do atendimento e do apoio material como práticas mais uma vez ligadas ao favor e não ao direito dos próprios usuários, é um dos principais aspectos que se procura combater na nova PNAS (MINISTÉRIO, 2004). Porém, a manutenção de práticas tradicionais no ambiente de implementação das políticas sociais afeta diretamente o acúmulo de capital social. Para $70 \%$ dos entrevistados a opinião deles não era respeitada nos CRAS, sendo que para os entrevistados que optaram por identificar o trabalho do CRAS como favor, o percentual foi para $73 \%$ (de entrevistados que responderam que as suas opiniões não eram respeitadas). Outra informação relevante é que mesmo para aqueles que afirmaram não terem a sua opinião respeitada, cerca de $70 \%$ deles responderam estar satisfeitos com o CRAS e com o trabalho dos técnicos (que não respeitaram a sua opinião).

Como pode ser constatado, o peso que a tradição cultural no Brasil possui em termos de dificultar a apropriação democrática das políticas sociais pela população usuária, ao invés do sentimento de que o atendimento material é favor que as elites e os membros do Estado fornecem, representa um impacto negativo significativo para o capital social e para a organização da população. 
Isso não pode esconder que o lado assistencial da PNAS, não apenas na leitura do texto legal, mas na sua prática, tem atendido materialmente setores vulneráveis da população brasileira. Porém, os efeitos políticos que são esperados pelos próprios proponentes da PNAS ainda não são significativos. O que, de certa maneira, lança um foco de luz à própria discussão sobre o papel do Estado na indução de capital social, ou qualquer outra condição favorável à organização e participação social e política.

\section{Conclusão}

O Brasil tem tido uma política social central no seu processo de inclusão social. Do ponto de vista político dessa população há sinais de crescimento social, mas ainda não político. Os desdobramentos participativos ainda não são fortes, e muitas vezes reforçam a velha tradição da cultura do favor e individualismo.

A aceitação dessa tarefa está presente tanto na PNAS quanto na NOB/SUAS de 2004. Na introdução da PNAS de 2005 consta que a nova política busca a "efetivação da assistência social como direito de cidadania e responsabilidade de Estado" (MINISTÉRIO, 2004, p. 5), sendo que na parte dos princípios há, dentre eles, o respeito à dignidade e autonomia do cidadão. Também nas diretrizes da PNAS há a previsão da participação da sociedade, por meio das suas associações, na formulação das políticas e do seu controle. No que toca ao CRAS, é esse servir para a convivência comunitária dos indivíduos e famílias, sendo que a intervenção prevista da PNAS via o CRAS é de levar em consideração a singularidade e os recursos simbólicos e afetivos das pessoas. No item 3 da gestão da PNAS, no que concerne ao desafio da participação dentro do controle social (item 3.1.6 da PNAS - MINISTÉRIO, 2004), há uma discussão sobre o perfil do usuário e de como ele foi, dentre outros detalhes, tutelado. Como tentativa de reversão desse contexto, há o chamamento para uma nova metodologia que consiga envolver mais as pessoas na participação e no consequente controle social. E isso começa dentro do próprio CRAS na medida em que as pessoas já se tornem protagonistas do seu próprio atendimento. Também na Norma Operacional Básica - NOB/ SUAS de 2004, 3 dos 11 eixos estruturantes dizem respeito ao direito à cidadania ativa: fortalecimento da relação democrática entre estado e sociedade civil; valorização da presença do controle social; participação popular/cidadão usuário ${ }^{7}$.

Porém, a pesquisa junto aos usuários de Caxias do Sul ainda não detectou esses objetivos terem sido atendidos. Um dos aspectos detectados foi a boa avaliação da PNAS e dos seus órgãos executores, o que não deixa de

\footnotetext{
${ }^{7}$ Parte dessa conclusão já foi apresentada no artigo A política de assistência social e a cultura do favor, apresentado no XII Encontro Nacional de Pesquisadores em Serviço Social, no Rio de Janeiro, em 2010 (LUCAS, SANTA e GONÇALVES, 2010).
} 
ser uma raridade no cenário brasileiro de insatisfação com o poder público e suas políticas.

João Ignacio Pires Lucas é Bacharel em Ciências Sociais, Mestre e Doutor em Ciência Política (UFRGS), Professor de Ciência Política e de Sociologia Jurídica da Universidade de Caxias do Sul. Foi Chefe de Departamento e Pró-Reitor de Planejamento da UCS.

E-mail: jiplucas@ucs.br

\section{Referências:}

ABREU, Haroldo. Para além dos direitos: cidadania e hegemonia no mundo moderno. Rio de Janeiro: Ed. UFRJ, 2008.

AMIN, Samir. Os desafios da mundialização. São Paulo: Letras \& Ideais, 2006.

ANDRADE, Ilza. Participação política não eleitoral ou partidária: associações, conselhos e orçamento participativo. In: MARTINS, Carlos Benedito (Org.). Ciência Política. São Paulo: ANPOCS, 2010. p. 377-400.

ARRIGHI, Giovanni. Adam Smith em Pequim: origens e fundamentos do século XXI. São Paulo: Boitempo, 2008.

BAQUERO, Marcello (Org.). Desafios da democratização na América Latina: debates sobre cultura política. Porto Alegre: Ed. UFRGS, 1999.

BAQUERO, Marcelo; PRÁ, Jussara Reis. A democracia brasileira e a cultura política no Rio Grande do Sul. Porto Alegre: Ed. da UFRGS, 2007.

BOSCHETTI, Ivannete. Seguridade social na América Latina. In: (Org.). Política social no capitalismo: tendências contemporâneas. 2. ed. São Paulo: Cortez, 2009. p. 174-195.

BRASIL. Presidência da República. Lei n. 8.742, de 07 de dezembro de 1993. Dispõe sobre a organização da Assistência Social e dá outras providências. Brasília, 07 de dezembro de 1993. Disponível em: <http://www.planalto.gov.br/ccivil_03/Leis/L8742.htm>. Acesso em: 15 jun. 2011.

Câmara dos Deputados. Projeto de Lei n. 3.077, de 25 de março de 2008. Altera a Lei n. 8.742, de 07 de setembro de 1993, que dispõe sobre a Assistência Social.

Disponível em:<http://www.camara.gov.br/proposicoesWeb/fichadetramitacao?idProposi cao $=387873>$. Acesso em: 15 jun. 2011. 
HOBSBAWM, Eric. Renascendo das cinzas. In: BLACKBURN, Robin (Org.). Depois da queda: o fracasso do comunismo e o futuro do socialismo. 2. ed. Rio de Janeiro: Paz e Terra, 1992. p. 93-106.

INGLEHART, Ronald; WELZEL, Christian. Modernização, mudança cultural e democracia: a sequência do desenvolvimento humano. São Paulo: Francis, 2009.

JAMESON, Fredric. Pós-modernismo: a lógica cultural do capitalismo tardio. 2. ed. São Paulo: Ática, 1997.

Modernidade singular. Rio de Janeiro: Civilização Brasileira, 2005.

LIMA, Marcos Costa (Org.). Dinâmica do capitalismo pós-guerra fria: cultura, tecnologia, espaço e desenvolvimento. São Paulo: Editora da UNESP, 2008.

LUCAS, João Ignacio Pires. Orçamento participativo, capital social e antipolítica: um estudo de caso em Caxias do Sul. In: BAQUERO, Marcello (Org.). Democracia, juventude e capital social no Brasil. Porto Alegre: Ed. UFRGS, 2004. p. 180-207.

LUCAS, João Ignácio Pires; SANTA, Allana Ariel; GONÇALVES, Andressa. A política de assistência social e a cultura do favor: a percepção dos usuários dos Centros de Referência em Assistência Social (CRAS) de Caxias do Sul. In: Encontro Nacional de Pesquisadores em Serviços Social, 22., 2010, Rio de Janeiro. Anais... Rio de Janeiro: Editora da ABEPSS, 2010.

MARINI, Ruy Mauro. Dialética da dependência. Petrópolis: Vozes, 2000.

MINISTÉRIO do Desenvolvimento Social e Combate à fome. Política Nacional de Assistência Social - PNAS. Brasília: Governo Federal, 2004.

2005.

Norma Operacional Básica - NOB/SUAS. Brasília: Governo Federal,

MOISÉS, José Álvaro. Os brasileiros e a democracia: bases sócio-políticas da legitimidade democrática. São Paulo: Ática, 1995.

MUNIZ, Egli. Os serviços de proteção social: um estudo comparado entre Brasil e Portugal. São Paulo: Cortez, 2005.

OLIVEIRA, Heloisa Maria José de. Cultura política e assistência social: uma análise das orientações de gestores estaduais. São Paulo: Cortez, 2003. 
OLIVEIRA, Iris Maria de. Cultura política, direitos e política social. In: BOSCHETTI, Ivannete et al (Org.). Política social no capitalismo: tendências contemporâneas. 2. ed. São Paulo: Cortez, 2009. p. 109-129.

PEREIRA, Potyara. Política social: temas \& questões. 2. ed. São Paulo: Cortez, 2009.

PUTNAM, Robert. Comunidade e democracia: a experiência da Itália moderna. Rio de Janeiro: Editora da Fundação Getúlio Vargas, 1996.

PUTNAM, Robert; FELDSTEIN, Lewis. Better together: restoring the American Community. New York: Simon \& Schuster, 2004.

ROJAS COUTO, Berenice. O direito social e a assistência social na sociedade brasileira: uma equação possível? 2. ed. São Paulo: Cortez, 2006.

SANTOS, Boaventura de Sousa. A crítica da razão indolente. 4. ed. São Paulo: Cortez, 2002.

SANTOS, Theotônio dos. Do terror à esperança: auge e declínio do neoliberalismo. São Paulo: Letras \& Ideias, 2004.

SENNETT, Richard. A cultura do novo capitalismo. Rio de Janeiro: Record, 2006.

A corrosão do caráter: as consequências pessoais do trabalho no novo capitalismo. 14. ed. Rio de Janeiro: Record, 2009.

SORJ, Bernardo; MARTUCCELLI, Danilo. O desafio latino-americano: coesão social e democracia. Rio de Janeiro: Civilização Brasileira, 2008.

WOOLCOCK, Michael. Social capital and economic development: toward a theoretical synthesis and policy framework. Theory and Society, Netherlands, v. 27, n. 2, p. 151-208, apr. 1998. 